\title{
Nutrigenomics: Opportunities and Challenges in Bangladesh
}

\author{
Md Nur Kabidul Azam ${ }^{1}$ and Md Nasir Ahmed ${ }^{2 *}$ \\ ${ }^{1}$ Department of Genetic Engineering \& Biotechnology, Jessore University of Science \& Technology, Jessore, Bangladesh
}

${ }^{2}$ TechB Nutrigenomics, Dhanmondi, Dhaka, Bangladesh

*Corresponding author: Md Nasir Ahmed, TechB Nutrigenomics, Dhanmondi, Dhaka, Bangladesh

\section{Opinion}

The Authors of this article has been working on ethnopharmacology and natural product science for the last one decade. They have been involved with several ethnic and traditional medication system development projects and also achieved recognitions in the medicinal plant sector of Bangladesh. Recently they have raised their interests on Nutrigenomics to introduce the "Personalized Nutrition" aiming to evolve the health maintenance in Bangladesh. The goal of this paper is to discuss opportunities and challenges for the next generation medicine in Bangladesh.

\section{Understanding Nutrigenomics}

The term Nutrigenomics compiled by Nutrition and Genetics, is a powerful tool that refers to the study of how nutrients or food derived bioactive compounds can affect human's gene expressions through diet. Nutrigenomics focuses at how SNPs (single nucleotide polymorphisms) interact with diet and diseases. According to Dr. Christine Houghton [1], Nutrigenomics identifies certain food derived molecules which have the greatest potential to "switch on" the protective genes and those that can "switch off" the disease promoting genes. Examples given by world's top nutrigenomics scientist Dr. Ahmed El-Sohemy in an interview [2]:

I. Compounds found in broccoli can switch on a gene that helps the body detoxify some of the chemicals we are exposed to everyday. This Gene is missing in about $20 \%$ of the general population who won't get the detoxification benefits.

II. A study published in the Journal of the American Medical Association, revealed that caffeinated coffee show that drinking coffee lowers the risk of heart attacks for some individuals. But in other individuals the same dose of coffee actually increases the risk of heart attacks.

\section{Understanding Personalized Nutrition}

Nutrition means the study of how nutrients are used in human metabolism and the process of being nourished by food derived bioactive compounds. Personalized Nutrition is based on the approach that individualized nutritional advice, products or services and personalization can be based on [3]:

I. Biological evidence of differential responses to food dependent on genotypic or phenotypic characteristics.

II. Analysis of current behavior, preferences, barriers and objectives and subsequent delivery of interventions.

\section{Market scenario of Nutrigenomics}

Although the implementation of nutrigenomics remains controversial but the market for nutrigenomics is growing at a tremendous speed. The global nutrigenomics market size was valued at USD 252.20 million in 2017 and the market is expected to reach USD $17,313.5$ million by 2023 . Nutrigenomics market in Europe is growing at a CAGR of $17 \%$ followed by Asia Pacific nutrigenomics market is expected to grow at a CAGR of $17.1 \%$ during the forecasted period. Middle East is domination market by holding $64.3 \%$ of the Middle East and Africa market share [4]. Increasing awareness among consumers and prevalence of metabolic diseases, growing trend of personalized diet among athletes, rising obese population and increasing healthcare expenditure and advancements in technology has driven the growth of the nutrigenomics market spontaneously [5-6].

\section{Opportunities and challenges in Bangladesh}

According to a study [7] published on 2008, "the challenge in bringing personalized nutrition to the market lies in developing 
diagnostic, nutritional and service solutions. We have to identify consumer demands, define biomarkers of bioavailability, bio efficacy and disposition, assess measuring technologies, and translate research into business models". However, Bangladesh is a country of huge medicinal plants resource and information on traditional medicine using plants could be a great source for practicing the nutritional medicine in this country that would be the next generation personalized drugs. In the recent year, government has decided to start Human Genome Sequencing Research [8] and also determined to establish "Bangamata National Cellular and Molecular Research Center" to explore the development of healthcare system. Apart from, botanical supplements are the greatest source of nutritional diet because they contain various bioactive compounds those which can fulfill the nutritional demands and boost up the body's immune system.

Above all these discussions, it can be expected that nutrigenomics could bring a new paradigm in medicine sector of Bangladesh. Investing in biotechnology and implementation of nutrigenomics, together can provide superior business model for developing the personalized nutrition industry as well as introducing next generation drugs in Bangladesh. Although there are a lot of initiatives and activities remaining to decide and both public and private sectors should work together to emphasize on increasing awareness about this new emerging science for the betterment of achieving healthy life style simply through diet.

\section{References}

1. https: //www.cell-logic.com.au/wp-content/uploads / NUTRIGENOMICS_Article_June_2013.pdf

2. https://www.precisionnutrition.com/nutrigenomics-research

3. Ordovas Jose M, Ferguson Lynnette R, Tai E Shyong, Mathers John C (2018) Personalised nutrition and health BMJ 361.

4. https://www.marketresearchfuture.com/reports/nutrigenomicsmarket- $4009 \% 20$

5. http://www.digitaljournal.com/pr/3663901

6. https://www.grandviewresearch.com/industry-analysis / nutrigenomics-market $\% 20$

7. Martin Kussmann, Laurent B Fay (2008) Nutrigenomics and personalized nutrition: science and concept. Per Med 5(5): 447-455.

8. https://www.dhakatribune.com/science/2019/01/16/humangenome-sequencing-research-begins-in-bangladesh
(C) This work is licensed under Creative

Submission Link: Submit Article

DOI: $10.32474 / D D I P I J .2019 .02 .000147$

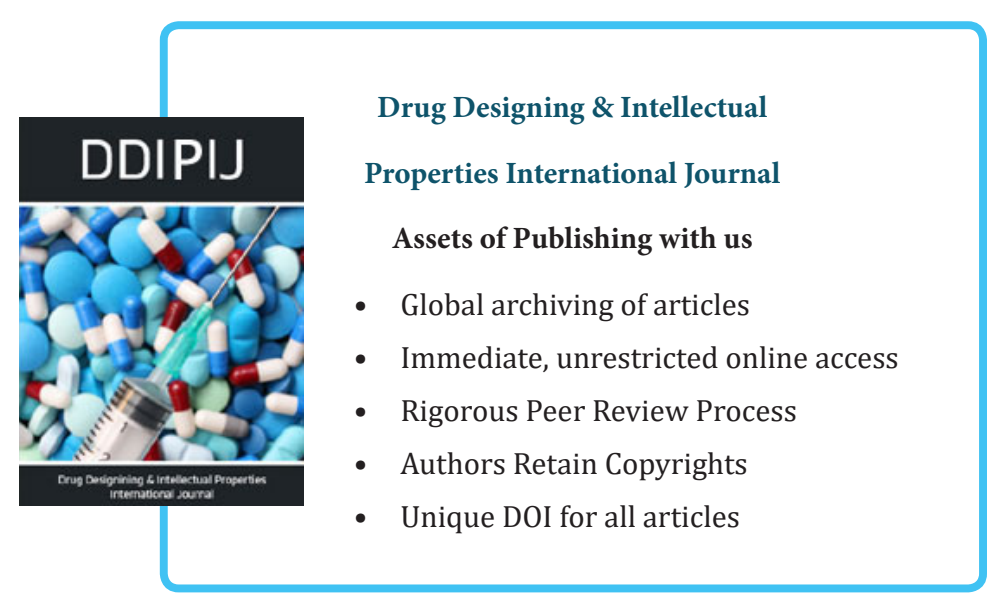

